\title{
GENERALIZED OSTEOPOROSIS IN OLD AGE
}

BY

\author{
C. M. KESSON, NOAH MORRIS*, and A. MCCUTCHEON
}

\section{From the University Medical Clinic, Stobhill Hospital and the Department of Materia Medica and Therapeutics, University of Glasgow}

It is well known that frequently the bones become rarefied in old age and it is commonly believed that this rarefaction or osteoporosis is a physiological process. Generalized osteoporosis, however, occurs in a considerable proportion of the population long before old age is reached. In the pre-senile group many factors have been held responsible for the thinning of bones, and it seems possible that they may also account for osteoporosis in the aged.

Attention was drawn to the subject of senile osteoporosis by Schmorl (1931), who studied the anatomy of the condition, and more recently by Meulengracht and Meyer (1936), who suggested that the main factor in the origin of the condition was long-standing calcium deficiency. This attractive hypothesis has received considerable support from Leitch (1936-37), Owen (1939), and Owen and others (1939). . If this view is correct, senile osteoporosis must be included among the disorders of calcium metabolism, attention must be paid to the dietary requirements of old folk, and the possibility considered of calcium metabolism in middle and old age differing from that of younger adults. Hyperparathyroidism (Hunter, 1930), hyperthyroidism (Aub and others, 1929) and pituitary basophilism (Freyberg and Grant, 1936) have been found to cause generalized osteoporosis at all ages, but it is unlikely that dysfunction of these endocrine glands is responsible for osseous rarefaction in the old. Statements are often made about the atrophy of the ductless glands in later life, but apart from the gonads there is no clinical or biochemical evidence that this takes place to a significant degree in health. The level of serum calcium does not suggest overactivity of the parathyroids, and the blood cholesterol values fail to reveal any alteration in thyroid activity. Albright and others (1941), however, as a result of a study of osteoporosis in 42 patients between the ages of 45 and 65, 40 of whom were female, came to the conclusion that the menopause may be a potent factor in the production of the osteoporosis, and recommended the use of stilboestrol as a therapeutic agent. Black and others (1941) found that senile osteoporosis was four times commoner in females than

- We deeply regret to record that since this article was received for publication the death has occurred of Professor Noah Merris at the early age of 53 . His obituary notices at the time dealt fully with his many important contributions Noah Morris at the early age of 53 . His obituary notices at the time dealt fully with his many. important contributions Metabolic problems had always attracted him, and latterly he had given much attention to the cormparatively new and hitherto neglected subject of gerontology, which is closely linked with many forms of chronic rheumatism. Recently he had contributed to a discussion at the Heberden Society 
in males. The possibility of some dysfunction of the sexual hormones as a causative factor must, therefore, be considered. In old age there are two phenomena which are of considerable interest in the present discussion, viz., the decrease in muscular exercise, and the increasing incidence of vascular disease. It is well known that disuse, whether produced by forced inhibition of movement such as occurs from trauma, or by a nervous lesion as in hemiplegia, is often followed by increasing fragility of the bones. Similarly, it is possible that defective blood supply associated with occlusive arterial disease may prevent an adequate deposition of lime in the bones.

In the present investigation an attempt has been made to determine the part played by calcium intake and metabolism, gonadal insufficiency, disuse, and vascular disorders in the genesis of osteoporosis in the old. The age of 65 years has been taken as a suitable point to divide middle from old age. Before, however, discussing pathogenesis, we must consider the criteria of senile osteoporosis and its symptomatology.

Before any special investigation each patient was examined with a view to excluding those suffering from conditions such as rheumatoid arthritis and osteoarthritis, which of themselves might be responsible for an osteoporotic condition of the bones. Serological tests were also carried out in order to eliminate the possibility of syphilis being an aetiological factor.

\section{Diagnosis}

It may be stated at once that neither clinical manifestations nor changes in blood chemistry suffice to detect generalized osteoporosis. Indeed, as will be seen later, radiography is the only satisfactory method at present available for the diagnosis of this condition, and here again care and experience are necessary to avoid fallacies arising out of differences in radiographic technique.

Radiography.-Films were taken of : (a) the right half of the pelvis, including the right hip joint and the proximal half of the right femur ; (b) the left shoulder joint, including the proximal two-thirds of the left humerus ; (c) the right hand ; (d) the left foot ; (e) the left knee joint, including the lower end of the left femur and upper ends of the left tibia and fibula ; and (f) the lumbar vertebrae. A large portion of the skeleton was thus examined radiographically, and it was, therefore, possible to exclude multiple arthritis. The routine technique ensured that the radiographic pictures from different patients could be compared with a degree of accuracy sufficient for the purpose of diagnosis.

The diagnosis of osteoporosis in any one bone was based on a consideration of the following two points. 1. Absorption of the transverse trabeculae. This is probably the earliest sign to be detected on a radiograph. In severer degrees of osteoporosis absorption of longitudinal trabeculae is also seen. 2. Diminution in the density of the bone shadow when compared with those obtained from a series of films taken of similar regions in healthy, well-nourished subjects. It may be stated that with the latter no difference can be detected in the $x$-ray densities of the skeleton among the various age groups.

It is more difficult to determine when osteoporosis is generalized, and any criterion is open to dispute. It is probable that in the earliest stage generalized osteoporosis may be apparent in only one region, and even when it has existed for some time it is inevitably more pronounced in some bones than in others. Accordingly difficulty in the diagnosis of early cases is inevitable 
unless rigid adherence is given to well defined standards. For the present investigation it was determined to include only those cases showing osteoporosis in at least three of the sites mentioned in a previous paragraph. This standard we believe is fairly strict : it excludes slight or commencing osteoporosis, but has the advantage of only including cases in which the diagnosis is not in reasonable doubt.

It is of interest at this point to consider which parts of the skeleton are most commonly affected by rarefaction. Black and others (1941), from an investigation of 23 cases of senile osteoporosis, concluded that rarefaction was most marked in the vertebrae. In "menopausal osteoporosis" Albright and others (1941) found that the spine and pelvis were commonly involved, while the long bones were affected only in the more severe cases. Our findings in the present series indicate most marked involvement in feet, hands, and spine in that order. It must be admitted, however, that it is more difficult to be certain of osteoporosis in the spine than in other regions.

The radiographic appearance of the vertebrae in senile osteoporosis corresponds with the anatomical changes described by Schmorl (1926; 1931), who found thinning of the cortical bone and enlargement of the marrow spaces and medullary cavity and, in severe cases, collapse of the vertebral bodies and expansion of the nucleus pulposus and intervertebral disc, producing the " fish-tail" vertebra. Similar radiographic changes in the spine associated with osteomalacia, osteitis deformans, and osteitis fibro-cystica do not cause confusion, since these diseases can be differentiated by other features. In senile osteoporosis kyphosis is commoner than scoliosis, while the reverse holds true for osteomalacia. Again in osteomalacia deformities of the pelvis and long bones are common, while they are rarely if ever found in senile osteoporosis. In senile kyphosis Beadle (1931) described a necrosis of the anterior portion of the annulus fibrosus resulting in the approximation of the vertebrae with resulting ankylosis, a condition revealed by $x$-ray examination.

Fractures bf osteoporotic bones were observed in $8(25 \%)$ of 32 patients with generalized osteoporosis. Those involved the lower thoracic and lumbar vertebrae and the intracapsular portion of the neck of the femur. Similar findings were noted in a series of radiographs of the spines of 71 hospital patients over a period of three years, fractures being found in $17(24 \%)$ of the cases. Ghormley and others (1937), in a large series of patients with senile osteoporosis, observed fractures in $8 \%$ and stated that the commonest cause of pathological fractures, apart from breast cancer metastases, was senile osteoporosis.

Clinical Manifestations.-When symptoms are present, they generally include vague aches and pains in the lower dorsal and lumbar regions and at times also in the abdomen and thighs. Pain, however, may become severe. Stiffness and weakness of the back are at times complained of, and in advanced cases the patient may be unable to walk. Black and others (1941) found that in senile osteoporosis a dull backache with weakness may be present for years before a mild trauma produced by bending the back leads to collapse of the vertebra and a transient acute pain followed by an aggravation of the previous discomfort. Referred pains may also be felt in the neck and limbs. Albright and others (1941) have reported similar clinical pictures in osteoporosis occurring at the menopause. Black and others (1941) are of the opinion that the dull backache is the result of bone rarefaction and that the sharp pains sometimes experienced are caused by ballooning of the intervertebral discs and compression of the vertebrae, although these abnormalities are by no means always associated with pain. It is of course reasonable to assume that the degree of deformity is likely to be an important factor in the causation of discomfort, but the psychological reactions of patients to discomfort vary enormously. In our opinion it is unlikely that symptoms arise from osteoporosis per se, but they probably follow the onset of complications such as deformity of the spine.

In the present series only $10(31.3 \%)$ out of a total of 32 patients with generalized osteoporosis complained of pain or discomfort. In six of the ten the pain could 
be attributed to a gross deformity of the spinal column or to fractures of one or more vertebrae. During the years .1939, 1940, and 1941 in Stobhill Hospital, 181 patients over $\mathbf{4 0}$ years of age had their spines radiographed because of back pain; only $56(30.9 \%)$ showed evidence of osteoporosis. It is obvious, therefore, that symptoms, even when associated with osteoporosis, need not be attributable to the skeletal rarefaction.

The most frequent signs obtained on examination are tenderness over, and at times spasm of, the erector spinae muscles. When collapse of one or more vertebrae has occurred the spine is often shortened, throwing the skin of the back into transverse folds and approximating the lower ribs to the iliac crests. In a few cases the abdomen shows transverse folds of redundant skin as a result of shortening of the spine. Kyphosis is commonly present.

From a study of the incidence of symptoms and signs it is clear that they cannot be relied upon for the diagnosis of generalized osteoporosis, but they may be of importance in directing attention to a possible involvement of the skeleton.

Blood Chemistry.-The values for serum calcium, inorganic phosphorus, and "alkaline" phosphatase were determined (Table 1).

TABLE 1

SERUM CALCIUM, PHOSPHORUS, AND PHOSPHATASE. MEAN VALUES IN DIFFERENT AGE GROUPS

\begin{tabular}{|c|c|c|c|c|c|c|}
\hline \multirow{2}{*}{$\begin{array}{l}\text { Age } \\
\text { group }\end{array}$} & \multicolumn{2}{|c|}{ Calcium (mg.\%) } & \multicolumn{2}{|c|}{$\begin{array}{c}\text { Inorganic phosphorus } \\
\text { (mg. \%) }\end{array}$} & \multicolumn{2}{|c|}{ Phosphatase (units) } \\
\hline & Osteop. & No osteop. & Osteop. & No osteop. & Osteop. & No osteop. \\
\hline $\begin{array}{l}40-49 \\
50-59 \\
60-69 \\
70-79 \\
80-89\end{array}$ & $\begin{array}{l}9 \cdot \overline{9} \\
10 \cdot 1 \\
10 \cdot 2 \\
9 \cdot 8\end{array}$ & $\begin{array}{r}10 \cdot 1 \\
10 \cdot 6 \\
10 \cdot 4 \\
10 \cdot 1 \\
9 \cdot 5\end{array}$ & $\begin{array}{l}\overline{2: 7} \\
2 \cdot 9 \\
3 \cdot 9 \\
3 \cdot 4\end{array}$ & $\begin{array}{l}3 \cdot 3 \\
2 \cdot 3 \\
3 \cdot 4 \\
3 \cdot 6 \\
3 \cdot 2\end{array}$ & $\begin{array}{r}\overline{6 \cdot 6} \\
8 \cdot 5 \\
8 \cdot 7 \\
11 \cdot 2\end{array}$ & $\begin{array}{l}6.2 \\
6.9 \\
7.5 \\
6.7 \\
9.8\end{array}$ \\
\hline
\end{tabular}

The results for calcium and phosphorus show little difference between the osteoporotic and non-osteoporotic subjects, but in the older age groups the phosphatase tends to be higher in the presence of osteoporosis. On statistical examination, however, it would appear that only in the 70-79 age group.can any significance be attributed to the difference. Robertson (1941) obtained similar figures in a group of 15 healthy subjects over the age of 60 , and found that, when compared with those for subjects in the third and fourth decades, only the phosphatase values showed any difference which might be significant. We also compared a group of senile patients with a group in the third and fourth decades and found that the serum phosphatase was higher in the former. It would appear, therefore, that there is a tendency for the phosphatase to increase in the healthy subject in the later years of life, and that this increase is accentuated if osteoporosis is present. According to Gutman and others (1934) however, in generalized osteoporosis the phosphatase is slightly increased in the young and middle-aged but not in the old. Bodansky and Jaffe (1934), too, state that there is no increase of plasma phosphatase in senile osteoporosis. Decalcification produced by calcium 
deficiency (Bodansky and others, 1932), defective absorption (in non-tropical sprue) (Bodansky and Jaffe, 1934), or hyperthyroidism (Cantarow, 1936) are often associated with a rise in phosphatase value. Morris and Peden (1937) have put forward the view that an increase in plasma phosphatase value is dependent on a deficiency of calcium to meet the needs of active bone cells. If osteoblasts are not active there may be little change in plasma phosphatase even in the presence of gross calcium deficiency. It is possible, therefore, that the very small rise of plasma phosphatase in senile osteoporotics may be attributable to the fact that in elderly patients the bone cells tend to lose their vitality and, therefore, their capacity to increase their production of phosphatase. Another possibility is that in subjects with senile osteoporosis there may actually be a considerable reduction in the number of osteoblasts.

From the diagnostic point of view it is clear that biochemical examination of the blood is of no help except possibly to assist in the exclusion of conditions such as hyperparathyroidism or osteitis deformans.

Calcium and Phosphorus Contents of the Ribs.-Portions of ribs were obtained at autopsy from 7 osteoporotic subjects and 3 who had given no radiographic evidence of decalcification during life. Only one patient (aged 59 years )was below the age of 65.

\begin{tabular}{lllcccc} 
Osteoporosis & & & $\%$ & $\%$ Ca. & $\%$ P. & Ca $/$ P ratio \\
No osteoporosis & $\ldots$ & $\ldots$ & $\ldots(14.6-6.6) 10.6$ & $(8 \cdot 7-3 \cdot 2) 6 \cdot 1$ & $(1 \cdot 7-2 \cdot 1) 1.7$ \\
\hline
\end{tabular}

After removal of the soft tissues the ribs were dried, weighed, and ashed in an electric muffle. The calcium content was estimated by the method of Shohl and Pedley (1922) and the phosphorus by Youngburg's method (1930). The results indicate that the percentage mineral content was less in the osteoporotic subjects but the differences were not statistically significant. The absence of radiographic evidence of osteoporosis, however, should not be regarded as proof that no other disorder of mineral metabolism existed. In order to obtain reliable information of the composition of bones in healthy old age one should limit the examination to bones obtained from healthy, wellnourished subjects who have met with sudden death as the result of an accident.

\section{Incidence of Generalized Osteoporosis}

Of 80 patients examined, 32 were found to present radiological evidence of generalized osteoporosis. The percentage incidence of 40 is high and cannot be

TABLE 2

AGE AND SEX INCIDENCE OF GENERALIZED OSTEOPOROSIS

\begin{tabular}{c|c|c|c|c|c|c}
\hline \multirow{2}{*}{$\begin{array}{c}\text { Age } \\
\text { group }\end{array}$} & \multicolumn{3}{|c|}{ Male } & \multicolumn{4}{c}{ Female } \\
\cline { 2 - 4 } \cline { 5 - 6 } & $\begin{array}{c}\text { Total } \\
\text { No. }\end{array}$ & $\begin{array}{c}\text { Osteop. } \\
\text { No. }\end{array}$ & $\begin{array}{c}\text { \% Incidence } \\
\text { of osteop. }\end{array}$ & $\begin{array}{c}\text { Total } \\
\text { No. }\end{array}$ & $\begin{array}{c}\text { Osteop. } \\
\text { No. }\end{array}$ & $\begin{array}{c}\text { \% Incidence } \\
\text { of osteop. }\end{array}$ \\
\hline $40-49$ & 2 & - & - & 3 & - & - \\
$50-59$ & 6 & - & - & 5 & 2 & 40.0 \\
$60-69$ & 12 & 3 & $25 \cdot 0$ & 7 & 4 & 57.1 \\
$70-79$ & 17 & 3 & 17.6 & 17 & 13 & 76.5 \\
$80-89$ & 2 & 1 & 50.0 & 9 & 6 & 66.7 \\
\hline Total & 39 & 7 & 17.9 & 41 & 25 & 61.0 \\
\hline
\end{tabular}


taken as an indication of the prevalence of this condition in the general population, since all the subjects of the investigation were drawn from the poorest section of the community. Our results are of interest when age and sex distribution are considered.

Age.-In Table 2 the cases are separated into age groups, and although the number in each group is small it is evident that there is an increasing incidence of osteoporosis with increasing age.

It is interesting here to consider the findings obtained from a survey of radiographs of the spine in 227 patients over the period of the years 1939-41. All cases of carcinomatosis, myelomatosis, and other conditions known to produce rarefaction of bone were excluded. The results of the survey are shown in Table 3.

TABLE 3

AGE AND SEX INCIDENCE OF OSTEOPOROSIS OF THE SPINE (1939-41)

\begin{tabular}{c|c|c|c|c|c|c}
\hline \multirow{2}{*}{$\begin{array}{c}\text { Age } \\
\text { Group }\end{array}$} & \multicolumn{3}{|c|}{ Male } & \multicolumn{3}{c}{ Female } \\
\cline { 2 - 6 } & $\begin{array}{c}\text { Total } \\
\text { No. }\end{array}$ & $\begin{array}{c}\text { Osteop. } \\
\text { No. }\end{array}$ & $\begin{array}{c}\text { \% Incidence } \\
\text { of osteop. }\end{array}$ & $\begin{array}{c}\text { Total } \\
\text { No. }\end{array}$ & $\begin{array}{c}\text { Osteop. } \\
\text { No. }\end{array}$ & $\begin{array}{c}\% \text { Incidence } \\
\text { of osteop. }\end{array}$ \\
\hline $40-49$ & 47 & 7 & $14 \cdot 9$ & 30 & 2 & $6 \cdot 7$ \\
$50-59$ & 40 & 9 & $22 \cdot 5$ & 23 & 7 & $30 \cdot 4$ \\
$60-69$ & 25 & 10 & $40 \cdot 0$ & 33 & 18 & $54 \cdot 5$ \\
$70-79$ & 13 & 6 & $46 \cdot 2$ & 9 & 8 & $88 \cdot 9$ \\
$80-89$ & 4 & 1 & $25 \cdot 0$ & 2 & 2 & $100 \cdot 0$ \\
$90-99$ & 1 & 1 & $100 \cdot 0$ & - & - & - \\
\hline Total & 130 & 34 & $26 \cdot 2$ & 97 & 37 & $38 \cdot 1$ \\
\hline
\end{tabular}

Here also it is evident that the incidence of osteoporosis increases with advancing years. Our figures are very similar to those published by Burrows and Graham (1945) for their own series and those of Lance and others (1938), Ravault and others (1939) and Meulengracht (1939). The diminishing number of patients in the last two decades of their combined series we believe may be explained by the smaller numbers surviving to these ages.

Sex.-A study of the sex distribution of the patients with osteoporosis shows that there is a significant predominance of generalized osteoporosis in the female. This is in accord with the findings of Burrows and Graham (1945). When allowance is made for the age grouping, one finds that the condition is 2.8 times more frequent among female patients. In the group of cases with spinal osteoporosis the increased incidence in women is not so marked $(1 \cdot 3)$ but is still significant. These findings are in accord with the fact that intracapsular fracture of the neck of the femur in old patients is much more common in women than in men, since this fracture is generally associated with an osteoporotic condition of the bone. Black and others (1941) in a series of 208 cases of senile osteoporosis of the spine, found that the ratio of male to female patients was $1: 4$. Albright and others (1941) found that of 42 osteoporotic patients between 45 and 65 years of age only 2 were males. 
It is clear, therefore, that after the age of $\mathbf{5 0}$ the female is more liable to suffer from rarefaction of the skeleton.

\section{Aetiology \\ Alteration of Calcium Metabolism}

Calcium in the Diet.-Meulengracht and Meyer in 1936, from a study of five patients, suggested that long-standing calcium deficiency played an important part in the causation of senile osteoporosis. Two years later Meulengracht reaffirmed this view in discussing the pathogenesis of osteoporosis in a patient with a history of repeated purgation resulting from sodium sulphate medication. That numbers of adults in this country lived in pre-war years on diets which failed to supply the estimated physiological requirements of calcium has been shown by Orr (1937), and this is of particular importance in the class of elderly patient admitted to the wards of a municipal hospital. Experimentally it has been demonstrated in pigs (McGowan, 1933), dogs of all ages (Jaffe and others, 1932), and cows (Becker and others, 1934) that defective intake of calcium leads to osteoporosis. These findings suggest that a similar condition in the adult human subject may result from a deficiency of lime in the diet.

If defective intake of calcium is the cause of generalized senile osteoporosis one would expect to be able to cure the condition by treatment with adequate amounts of calcium in the diet. Conclusive proof of this has yet to be demonstrated. Black and others (1941) investigated a series of 208 patients suffering from senile osteoporosis of the spinal column, of whom 167 were female and 41 male. Treatment.with an adequate diet, which included foods such as milk, cheese, and eggs, supplemented with salts of calcium and phosphorus and with vitamin D, was given. Of these patients, 72 were followed up for periods up to 9 years and averaging 2.3 years from the initial examination. Symptomatic improvement was found in $54 \%$ of patients treated with calcium and phosphorus, with vitamin $\mathrm{D}$, or with all three. In patients having none of these, $33 \%$ were benefited. In the group on treatment with calcium, phosphorus, and vitamin $\mathrm{D}$, only $43 \%$ treated for less than 6 months showed improvement, but of those treated for 6 months or longer $70 \%$ were improved symptomatically. Follow-up radiographs were available in 18 cases, the average period of treatment being 29 months. In no case was there sufficient change to enable the radiologist to say that it was due to recalcification and not to variation in the technique used in taking the films. It is interesting to compare the above findings with those recorded by Maxwell (1929-30) in cases of osteomalacia associated with pregnancy, in which symptomatic relief was obtained after $1 \frac{1}{2}$ or 2 months' administration of calcium and vitamin D. Meulengracht (1939) in a series of 18 cases of osteomalacia of the spinal column, 6 male -and 12 female all over 40 years of age, also obtained relief of symptoms with treatment by good diet supplemented by calcium and vitamin D. Subjective improvement, however, may not always be reliable evidence as a test of the efficiency of the drug therapy, as is illustrated by the following three cases of generalized senile osteoporosis. 
(a) Mrs. A. J., 73 years, had suffered from lumbar pain, which radiated into the abdomen and also down into the thighs, for four months before admission to hospital. Rest in bed without any drug therapy relieved the acute pain in a few days, and complete relief was experienced in four weeks. (b) $\mathrm{O}$. McC., a male, aged 68 years, had had occasional pains in the back for nine years, and two weeks before admission to hospital he developed severe lumbar pain which disappeared gradually with rest in bed and the oral administration of a "placebo" containing infusion of gentian. He believed that the medicine " did him good". (c) Mrs. W. N., 73 years, complained of pain in the back and abdomen for three weeks before admisssion, and rest in bed for five days did not give relief but a " placebo" produced striking relief within two days.

The assessment of symptomatic relief with drug therapy, therefore, requires careful and cautious consideration. Black and others (1941) noted that $33 \%$ of their patients who were not receiving calcium, phosphorus, or vitamin $D$, apart from the amounts contained in their food, improved symptomatically. That the percentage of cases relieved symptomatically jumped from $43 \%$ to $70 \%$ when those before and after six months' treatment were contrasted, should also, however, be especially noted. If the objective tests of $x$-ray examination showed improve-

- ment it would be very much more important and convincing evidence of the specific effect of calcium enrichment of the diet.

In order to test the effect of calcium enrichment of the diet on the radiograph of the skeleton in generalized osteoporosis, 10 patients all over 65 years of age were given, in addition to ordinary hospital diet, $1 \mathrm{~g}$. of calcium per day in the form of calcium gluconate or calcium phosphate. The hospital diet itself contained about $0.7 \mathrm{~g}$., so that in all the daily intake of calcium approximated to $1.7 \mathrm{~g}$., an amount considerably in excess of the estimated requirements of a normal adult of $70 \mathrm{~kg}$. weight. This treatment was in all cases continued for more than six months, and in one for more than a year. Radiographic examinations were repeated at monthly intervals, but in no instance was any change demonstrable in the condition of the bones.

These findings correspond with those of Black and others (1941), who were unable to detect any appreciable change in senile osteoporosis of the spine treated for as long as twenty-nine months. The criticism might be made that, in view of the generalized nature of the condition, the period of treatment was not long enough in the present series to allow of sufficient calcium to be deposited for the production of changes in the skiagram. It is well known that localized osteoporosis such as is seen in fractures or in rickets shows $x$-ray evidence of healing within a matter of weeks, but in these cases only relatively small areas of bone require intensive recalcification. Records are, however, available to indicate that, even in patients with marked generalized rarefaction of the skeleton, radiographic changes can be readily detected after several months' therapy. Maxwell (1929-30) has described osteomalacia with kyphosis in a woman aged 37 years who showed radiographic evidence of recovery within two months of the commencement of treatment. Hunter and Turnbull (1931-2) have recorded the case history of a woman aged 33 years with osteomalacia. Radiography showed osteoporosis of most of the skeleton. After three months' treatment the pains disappeared, and after seven months $x$-ray examination revealed a very considerable degree of re-calcification. In view of these records it is tempting to suggest that six months is a reasonable time within which to expect radiographic improvement in generalized senile osteoporosis if changes are going to occur. If this assumption 
be accepted, the conclusion seems to be that neither the findings of Black and others (1941), nor those obtained in the present investigation, support the view that deficient calcium intake is the sole cause of senile osteoporosis although they do not rule out the possibility of its being a factor.

Determinations of serum calcium, inorganic phosphorus, and " alkaline " phosphatase were carried out in the same series of patients. In some instances there was a slight rise in the calcium and phosphorus values and a fall in the phosphatase, but these changes cannot be considered of significance, since all were within the accepted ranges for normality.

Absorption and Retention of Calcium.-Several factors are involved in promoting the absorption and retention of lime. It may be of interest to consider some of these briefly in relation to patients with senile osteoporosis.

Apart from the actual amount of calcium in the diet, lack of vitamin D might appear to be of the greatest importance. A deficiency of this factor is undoubtedly important in the pathogenesis of osteomalacia. A comparison between this disease and senile osteoporosis is instructive. The clinical pictures may be very similar. Stiffness, weakness, and pain in the back are symptoms common to both ; tenderness and shortening of the spine are also found in both conditions. Deformities of the spine such as kyphosis and scoliosis have been described, but kyphosis is more commonly associated with senile osteoporosis, whereas scoliosis, according to Maxwell (1929-30), is more frequent in osteomalacia. The radiographic appearances of the lesions in the spine may be identical. In puerperal osteomalacia, however, deformities of the pelvis and long bones of the lower limbs may be marked, whereas these are not found in senile osteoporosis. Furthermore osteomalacia may affect the skull (Hunter and Turnbull, 1931-2), whereas in senile osteoporosis this is uncommon (Albright and others, 1941). According to Meulengracht the blood chemistry in osteomalacia is normal with the occasional exception of a slightly raised plasma phosphatase, which is similar to the findings in senile osteoporosis. In the response to calcium and vitamin D therapy there is, however, a great difference. Symptomatic improvement has been reported in both conditions, but while radiological proof of cure can be readily obtained in osteomalacia, sometimes within relatively short periods, it has yet to be demonstrated in senile osteoporosis.

Conditions in the alimentary tract exert an important influence on the absorption of lime. The presence of free hydrochloric acid in the stomach, by decreasing the $p \mathrm{H}$ of the intestinal contents, favours calcium absorption. Any failure in gastric secretion which might occur with advancing age may, therefore, impair the utilization of dietary calcium. It is well known that the ability to secrete hydrochloric acid in the gastric juice is reduced with advancing years (Faber, 1927).

In another investigation of 81 patients over the age of 65 we found that $46(56.8 \%)$ showed achlorhydria. It is possible, therefore, that this may be a factor in the production of senile osteoporosis. It can, however, exert a significant effect only when dietary calcium is poor, since with an adequate intake of lime normal assimilation does occur in healthy subjects with achlorhydria (Schmidt and Greenberg, 1935). Furthermore, the results obtained in the course of the present investigation do in fact show that whether or not hydrochloric acid appears in the gastric juice retention of lime takes place if an adequate amount is ingested.

Intractable diarrhoea from any cause is likely to produce failure of calcium absorption, as is well known in coeliac disease and idiopathic steatorrhoea. Meulengracht (1939) stresses the abuse of laxatives as a potent factor in some patients with osteomalacia of the spine. Careful inquiry into the previous history of each of our patients failed to reveal any possibility that diarrhoea might have been a factor in the mal-absorption of lime. Throughout their stay in hospital none of the subjects of this study suffered from diarrhoea, slight or severe.

The presence of bile in the gut is necessary for proper fat absorption, and if this is deficient the excess fat unites with calcium to form insoluble soaps. Inspection of the faeces in all cases, with chemical analyses in a few, showed that there was no deficiency of bile products or excess of fat in the stool. 
It is reasonable, therefore, to assume that the conditions necessary for adequate absorption of lime are generally fulfilled. The question may now be raised whether old people do, in fact, absorb calcium.

As regards young adults and middle-aged people, it has been shown by Robertson (1941) that there is no difference in calcium metabolism. He compared the metabolism of 12 adults of ages ranging from 19-39 years with that of 12 adults aged from 40-60 years, and found no significant difference. Owen (1939) and Owen and others (1939) carried out calcium balance experiments in older male subjects, including patients in the senile age group, and found that these patients were capable of storing calcium and phosphorus when given diets containing more of these elements than their customary intake. Furthermore Owen and others demonstrated the same capabilities in 5 patients, aged from 69-79 years, suffering from senile osteoporosis. These findings suggest that calcium metabolism in the senile age group is similar to that in the younger age groups.

The following calcium balance studies were undertaken to determine whether adequate absorption of calcium and phosphorus was possible in senile patients. Nine patients were selected, 8 of these having generalized osteoporosis and one without any radiographic changes in the skeleton. The diet in each case had a calorie value of approximately 1,900 , and consisted of milk, bread, cereals, potato, margarine, tinned meat, and tea. Each patient was given this diet for one week to allow adjustments in quantities in order to suit individual appetites. The diet was then standardized for each patient, and after a preliminary period of one week the calcium and phosphorus intake and output were determined. The intake was computed from the analyses of aliquot portions of each article of food, while urinary and faecal analyses were carried out on weekly collections of the excreta for two weeks. Thereafter each patient was given measured amounts of calcium gluconate $(10 \mathrm{~g}$.) or calcium phosphate (calfos, $10 \mathrm{~g}$.) and in the former cases 1,000 units of vitamin D each day, in addition to the standard diet. A week was then allowed for stabilization before the intake and output were again determined for two periods of one week. All patients were confined to bed throughout the entire period of metabolic study. Calcium was determined by the method of Shohl and Pedley (1922), phosphorus by Youngburg's method (1930).

The standard diet provided an average intake of $847 \mathrm{mg}$. of calcium per day, which is signifcantly in excess of the maintenance figures of 450 (Sherman, 1920), 550 (Leitch, 1936-7) or 520 (Owen, 1939). On this diet only two of the osteoporotic patients showed a net loss of calcium : in one instance this was insignificant ( $23 \mathrm{mg}$. per day), while in the other it amounted to $141 \mathrm{mg}$. The others had positive calcium balances varying from 247 to $502 \mathrm{mg}$. per day. When the calcium salts were given, the increase of calcium intake produced in every instance a marked increase in calcium retention varying from $217 \mathrm{mg}$. to $1,106 \mathrm{mg}$. per day. Higher retentions were obtained with calcium gluconate and vitamin D than with calcium phosphate, in spite of the fact that the calcium intake was always higher with the latter preparation. It is possible that vitamin $\mathbf{D}$ was responsible for the greater retention of lime. Another point of interest is that on calcium gluconate and vitamin $D$ the patient without osteoporosis had a lower calcium retention than the 4 osteoporotic subjects on the same régime. In all instances the main route of calcium excretion was the bowel: the addition of lime to the diet, whether in the form of gluconate or phosphate, did not appreciably alter the actual amounts of calcium lost in the urine.

The average phosphorus content of the standard diet was $635 \mathrm{mg}$. per day, which is lower than the maintenance estimate of Sherman and others (1920). In 5 of the 8 osteoporotic patients, and in the 1 other subject there was a loss of phosphorus ( 32 to $271 \mathrm{mg}$. per day), while in the remaining 3 patients with osteoporosis the positive balance was low ( 19 to $156 \mathrm{mg}$. per day). In all but two patients the phosphorus retention increased slightly ( 81 to $250 \mathrm{mg}$. per day) with administration 
of calcium gluconate and vitamin D, and markedly (357 to $504 \mathrm{mg}$. per day) with calcium phosphate. In all but two patients the greater part of the phosphorus was lost in the urine and the addition of gluconate or phosphate to the diet did not appreciably alter the percentage of phosphorus lost in the urine.

These balance studies indicate clearly that aged patients with generalized osteoporosis are capable of absorbing and retaining calcium and phosphorus when these substances are present in adequate amounts in the diet. We know, however, that prolonged administration of lime salts to patients with senile osteoporosis produces no change in the radiographic appearances of the bones. The question, therefore, arises whether these patients can maintain absorption of lime and phosphorus at a high level over a period sufficiently long to permit the deposition of enough mineral to produce an alteration in the $x$-ray picture. Adams and others (1935-6) determined calcium and phosphorus retention in a woman aged 65 years under treatment for senile osteoporosis. Over a period of 19 weeks they found that the daily retention amounted to $220 \mathrm{mg}$. of calcium and $100 \mathrm{mg}$. of phosphorus.

In two patients, one with and one without osteoporosis, we determined the mineral retention after periods of fourteen and eighteen weeks respectively on calcium gluconate and vitamin $\mathbf{D}$. The positive calcium balance was maintained in both cases, although it was not nearly as marked in the osteoporotic case as in the control. The phosphorus balance was found to have changed from positive to negative in the osteoporotic case and vice versa in the normal one. In view of the low intake of phosphorus it is.rather surprising that both cases were not found to be in negative balance.

These results show that both osteoporotic and normal patients are capable of continued storage of calcium over a period of about three or four months if placed on intakes which are much higher than those to which they are accustomed. They confirm the findings of Adams and others (1935-6) that positive balance of calcium may be maintained over a prolonged period in a patient suffering from senile osteoporosis. Further investigation over longer intervals of time would need to be conducted in order to find out if this retention would continue in cases so treated. It is worthy of note-that the control case showed a considerable retention of calcium, which was in fact much greater than that of the osteoporotic one. This suggests that stress should not be-laid on the retention of calcium in the osteoporotic case. It may be that the body would adapt itself to the higher intake, given time, and attain equilibrium. It is known that as the intake rises so does the daily requirement for maintenance (Robertson, 1941), and one would expect an initial period of increased retention prior to equilibrium on a higher level. Similarly, adjustment to intakes which are lower than the accepted minimal levels may be found (Owen and others, 1939). It is likewise to be expected that there would be a lag period during which there would be a negative balance before such equilibrium were established.

These results indicate that elderly patients with or without osteoporosis show no inability to absorb and retain calcium and phosphorus when put on suitable intakes, and that the absorption and retention of calcium may continue over a period of fourteen weeks. It seems reasonable to conclude that deficiency of 
absorption and retention of minerals do not ordinarily play a part in the aetiology of senile osteoporosis.

Inability to Utilize Calcium for Bone Formation.-It is feasible that although absorption of calcium and phosphorus is normal in senile osteoporosis these minerals may be used for purposes other than bone formation. For example, the calcium may be deposited in the walls of arteries, ligaments, etc. Reference will be made later to the relationship of arteriosclerosis and calcification of the arteries to senile osteoporosis. Suffice it to say here that in none of the 10 osteoporotic patients treated for a period of several months with calcium gluconate and vitamin D was any alteration observed radiographically in the calcification of the arteries. It may be that the process by which senile osteoporosis is produced is irreversible. Perhaps prolonged reduced intake of mineral leads to osteoporosis in senile patients and once this has been brought about it cannot be cured by increasing the intake, although the process may be halted by such treatment. This would explain why improvement has so far not been demonstrated radiographically in patients treated over long periods of time although symptomatic improvement is often obtained. Alternatively it is possible that senile osteoporosis develops over a number of years and, correspondingly, inprovement in the condition may be so slow that radiographic proof of cure might not be available until treatment had continued for a number of years. Further investigation is obviously necessary before this problem can be elucidated. It may be significant that in his anatomical description of the condition Schmorl (1931) states that the surfaces of the trabeculae are clean and smooth and indicate a long, slow vascular resorption, and that the individual trabeculae are much thinner and fewer than in normal although their architectural structure is maintained. This finding would indicate a slow development of the condition, and as the trabeculae are fewer than normal it is feasible that the formation of the new trabeculae may not be possible, as it is well known that repair of bone in old people is often uncertain and incomplete, e.g. in the healing of fractures. Addvanced senile osteoporosis, therefore, might prove to be irreversible.

\section{LACK OF EXERCISE}

Localized rarefaction of limb bones as a result of disuse is not uncommon (Harris, 1933). It seems reasonable, therefore, to consider the part played by lack of exercise in the production of generalized osteoporosis. As individuals pass middle age they tend to become less active either from choice or from the crippling effects of the chronic rheumatic conditions. The spine and the lower limbs are the most frequent sites of osteoporosis, but the hands which are generally actively used, even by patients confined to bed, are not infrequently involved. Black and others (1941) in considering the problem, state that senile osteoporosis may occur in people who have always been very active.

In our series of patients we attempted to determine whether there was any difference between osteoporotic and non-osteoporotic subjects with reference to the duration of confinement to bed before investigation. We found that in patients with osteoporosis the average period of confinement to bed was 5.8 months, whereas for the others it was 4.7 months. There are obviously 
many fallacies in this computation, but the difference seemed sufficient to warrant the investigation of the incidence of ostooporosis in a group of post-encephalitic patients, some of whom had been partially or completely disabled for many years. These patients had been inmates of a special postencephalitic ward for periods of up to seventeen years. Dietaries were adequate, the daily intakes of calcium and phosphorus amounting to 1.2 and $1.5 \mathrm{~g}$. respectively. Evidence of vascular disease (signs of arteriosclerosis) was obtained in only 1 of 34 male patients and 5 of 34 females. The age incidence of the males was 20 to 62 years, of the females 22 to 69 years. Values for serum calcium, inorganic phosphorus, and "alkaline" phosphatase fell within the recognized normal limits. No correlation was detected between the duration of the post-encephalitic state and the incidence of osteoporosis: indeed several patients without skeletal changes had suffered from the nervous disorder for longer than those with osteoporosis. This suggests that neurotrophic disturbance is not responsible for the rarefaction of the bones.

The incidence of osteoporosis in these subjects is shown in Tables 4 and 5.

TABLE 4 .

GENERALIZED OSTEOPOROSIS IN POST-ENCEPHALITIC PATIENTS : AGE AND SEX INCIDENCE

\begin{tabular}{l|c|c|c|c|c|c}
\hline \multirow{3}{*}{ Sex } & \multicolumn{2}{|c|}{ Below 50 years } & \multicolumn{2}{c|}{$50-59$ years } & \multicolumn{2}{c}{$60-69$ years } \\
\cline { 2 - 5 } \cline { 6 - 7 } & Osteoporosis & Total & Osteoporosis & Total & Osteoporosis & Total \\
\hline $\begin{array}{l}\text { Female } \\
\text { Male }\end{array}$ & 4 & 22 & 3 & 10 & 2 & 2 \\
\hline
\end{tabular}

TABLE 5

GENERALIZED OSTEOPOROSIS IN POST-ENCEPHALITIC PATIENTS : CORRELATION OF INCIDENCE AND INACTIVITY

\begin{tabular}{|c|c|c|c|c|c|}
\hline \multicolumn{3}{|c|}{$\begin{array}{l}\text { Degree of } \\
\text { disability }\end{array}$} & No osteoporosis & . Osteoporosis & $\begin{array}{l}\% \text { Incidence of } \\
\text { osteoporosis }\end{array}$ \\
\hline $\begin{array}{l}\text { Mild } \\
\text { Severe } \\
\text { Complete }\end{array}$ & $\begin{array}{l}\cdots \\
\cdots \\
\cdots\end{array}$ & $\begin{array}{l}\cdots \\
\cdots \\
\cdots\end{array}$ & $\begin{array}{r}24 \\
26 \\
5\end{array}$ & $\begin{array}{l}1 \\
5 \\
7 \\
-\end{array}$ & $\begin{array}{r}4 \\
16 \\
58\end{array}$ \\
\hline
\end{tabular}

Of the 13 patients with osteoporosis, 7 had been completely helpless for some years, 5 with considerable disability, including inability to walk, and only 1 with a mild disability. Of the 12 completely helpless patients, 7 had marked rarefaction of the bone. There is no doubt that in this series of post-encephalitic subjects there is a positive correlation between the degree of inactivity and the incidence of osteoporosis. In this group senility did not play a part, since 7 of the 13 osteoporotic patients were below 40 years of age and only 2 were above 60 .

The work of Black and others (1941), and indeed our own experience, indicates that osteoporosis does occur in subjects who have continued to live a fairly active life. Nevertheless, the incidence of osteoporosis in young patients who have been rendered helpless by the ravages of encephalitis lethargica suggests that lack of exercise may be an aetiological factor in rarefaction of the skeleton in old age.

\section{VASCular Disease}

Arteriosclerosis.- It is possible that arteriosclerosis, by limiting the nutritional supply of bone, might be a factor in the dimineralization of the skeleton found in 
old age. Harris (1933) states that in patients with hypertension and arteriosclerosis radiographic changes may be found in intervertebral discs and vertebral bodies. The distribution of senile osteoporosis is consistent with the suggestion that arteriosclerosis is of aetiological importance. In senile osteoporosis the feet are commonly affected to a marked degree, and it is known that sclerosis can be detected much sooner in the arteries of the lower limbs than elsewhere. In our patients over 40 years of age, 45 had macroscopic evidence of arterial calcification, and only 6 showed this in the vessels of the upper limbs. When, however, we determined the incidence of arteriosclerosis in patients with and without osteoporosis we found that there was no correlation between osteoporosis and vascular changes, detected by palpation of vessel-wall level of blood pressure or by radiograph.

Anaemia.-Osteoporosis has been found in association with certain forms of anaemia, such as sickle-cell anaemia, Cooley's anaemia, and acholuric jaundice. In our patients we found that the average haemoglobin level of the osteoporotic subjects was $12.7 \mathrm{~g}$. per $100 \mathrm{c.cm}$. and of the others $13.4 \mathrm{~g}$. The difference between these two figures was not significant, a result which coincides with our clinical impression that there is no correlation between senile osteoporosis and anaemia.

\section{ENDOCRINE IMBALANCE}

Silberberg and Silberberg (1943) have reviewed the literature on the influence of the endocrines on ageing of the skeleton. Many if not all the hormones have been reputed at one time or another to be of importance in the regulation of calcium metabolism. It is, therefore, worth while briefly to consider the possibility of some endocrine disorder being responsible, at least in part, for the development of senile osteoporosis.

Aub and others (1929) found that hyperthyroidism is associated with an increased loss of lime in urine and faeces, and if prolonged there may be marked osteoporosis. In our series of patients there was no evidence of hyperthyroidism, either clinical, metabolic, or biochemical. Hypersecretion of parathyroid hormone leads to the peculiar form of demineralization known as generalized osteitis fibrosa. In none of our patients did the $x$-ray picture bear any resemblance to that of von Recklinghausen's disease, nor did the values for serum calcium and phosphatase suggest this. Black and others (1941) found no abnormality of the parathyroid glands in three patients with senile osteoporosis. Osteoporosis is known to occur in association with pituitary basophilism and adrenal dysfunction (Freyberg and Grant, 1936; Black and others, 1941), but no evidence of pituitary or adrenal disorder was detected in any of our patients.

The Oestrogenic Hormones.-Albright and others (1941) reported a series of 42 patients, all with generalized osteoporosis, between the ages of 45 and 65 , the post-menopausal period. Only two patients were males. Oestrin therapy had a beneficial effect, and in view of this and the sex incidence the authors think the absence of oestrogenic hormone may be of importance in the pathogenesis of generalized osteoporosis in this age group. We determined the effect on serum calcium, phosphorus, and phosphatase levels of oral administration of 2-10 mg. stilboestrol daily for periods varying from ten days to six months. Of the 31 patients studied, 20 were male and 11 female: ages varied from 49 to 88 years. Significant changes in blood chemistry were not obtained. Five female patients with marked general osteoporosis were observed for the full period of six months' stilboestrol therapy. In no case could any alteration in the $x$-ray picture be detected.

As has previously been pointed out, there seems little doubt that after middle age the incidence of genefalized osteoporosis is greater in the female than in the make. It would appear from our results that lack of oestrogenic hormone does not play a very important part. It occurred to us that pregnancies during the reproductive period of life might impoverish the stores of lime, with 
the result that multiparae might more easily become the subjects of osteoporosis. Table 6 shows the incidence of skeletal rarefaction among nulliparae and multiparae, and it is evident that in this small group at any rate multiparity had some association with the development of osteoporosis. The use of the chi-square test indicates that there is a significant association between multiparity and osteoporosis, and this is consistent with the inadequate lime content of these women's diets at a time when the call for calcium was urgent and frequent.

TABLE 6

GENERALIZED OSTEOPOROSIS AND PARITY

\begin{tabular}{|c|c|c|c|c|c|c|}
\hline \multirow{2}{*}{$\begin{array}{l}\text { Age } \\
\text { group }\end{array}$} & \multicolumn{3}{|c|}{ Nulliparae } & \multicolumn{3}{|c|}{ Multiparae } \\
\hline & Osteop. & Total & $\begin{array}{l}\text { \% Incidence } \\
\text { of osteop. }\end{array}$ & Osteop. & Total & $\begin{array}{l}\% \text { Incidence } \\
\text { of osteop. }\end{array}$ \\
\hline $\begin{array}{l}\text { Below } 70 \\
\text { Above } 70 \\
\text { All ages }\end{array}$ & $\begin{array}{l}1 \\
5 \\
6\end{array}$ & $\begin{array}{r}6 \\
9 \\
15\end{array}$ & $\begin{array}{l}17 \\
56 \\
40\end{array}$ & $\begin{array}{l}5 \\
13 \\
18\end{array}$ & $\begin{array}{r}9 \\
16 \\
25\end{array}$ & $\begin{array}{r}56 \\
81 \\
72\end{array}$ \\
\hline
\end{tabular}

\section{Therapeutics}

When the cause of osteoporosis is known and can be removed the condition can be cured ; for example the administration of vitamin D with a generous supply of calcium to a patient with osteomalacia leads to a rapid recalcification of the bones. The prognosis in cases of senile osteoporosis is not so satisfactory, however, as the cause has not yet been accurately determined. From the evidence produced in our investigations we feel that endocrine disturbance, arteriosclerosis, and anaemia can be excluded, but that lack of exercise may play a minor part in the aetiology. Prolonged reduced intake of minerals is probably an important factor, although so far it has not been found possible to produce radiographic evidence of calcium deposition in the rarefied skeleton with a diet rich in calcium and phosphorus. This may be due either to the mineral loss being so great that a very lengthy period is required to restore it, or to the osteoporotic process being irreversible in aged patients. Inability to absorb and retain calcium and phosphorus was not a factor in the aetiology in our patients. Although no improvement was detected radiographically in patients treated with a high intake of minerals for periods up to fifteen months, no increase in the osteoporosis was noted. We are of the opinion, therefore, that if such a diet is taken, it is possible to prevent further decalcification and the occurrence of complications. We can further state that in none of our patients was there any indication that a daily intake of calcium well in excess of $1.0 \mathrm{~g}$. for periods of a year or longer had any significant effect on the systolic and diastolic blood pressures or on the haemoglobin concentration of the blood.

Although vitamin D has not been shown to be concerned in the aetiology, it is advisable to administer it in moderate doses in the light of our present knowledge.

Rest in bed and the exhibition of analgesics such as aspirin usually relieve the pains of osteoporosis. Local application of heat may also be beneficial. If vertebral complications warrant it, a spinal support is indicated. 


\section{Summary}

1. The age and sex incidence of generalized osteoporosis has been estimated in a series of 80 patients over the age of 40 years drawn from the poorer sections of the population of Glasgow. These findings have been compared with the incidence of osteoporosis of the spine in radiographs taken during the years 1939-41, of 227 patients over 40 years of age from the same strata of the community.

2. The clinical manifestations, blood chemistry, and radiological appearances are discussed.

3. An attempt has been made to determine the aetiology of generalized osteoporosis in the aged.

We are indebted to Dr. A. D. Briggs, Medical Superintendent, for permission to use hospital records, and to the Medical Research Council for grants in defrayment of expenses.

\section{REFERENCES}

Adams, M., Boothby, W. M., and Snell, A. M. (1935-6). Amer. J. Physiol., 114, 383.

Albright, F., Smith, P. H., and Richardson, A. M. (1941). J. Amer. med. Ass., 116, 2465.

Aub, J. C., Bauer, W., Heath, C., and Ropes, M. (1929). J. clin. Invest., 7, 97.

Beadle, O. A. (1931). M.R.C. Spec. Rept. Series, No. 161. London.

Becker, R. B., Neal, W. M., and Shealy, A. L., (1934). J. Dairy Sci., 17, 1.

Black, J. R., Ghormley, R. K., and Camp, J. D. (1941). J. Amer. med. Ass., 117, 2144.

Bodansky, A., and Jaffe, H. L. (1934). Arch. intern. Med., 54, 88.

- Jaffe, H. L., and Chandler, J. P. (1932). Proc. Soc. exp. Biol., N.Y., 29, 871.

Burrows, H. J., and Graham, G. (1945). Quart. J. Med., N.S., 14, 147.

Catarow, A. (1936). Internat. Clin. Philad., 1, 230.

Faber, K. (1927). Lancet, 2, 901.

Freyberg, R. H., and Grant, R. L. (1936). Arch. intern. Med., 58, 213.

Ghormley, R. K., Sutherland, G. C., and Pollock, G. A. (1937). J. Amer. med. Ass., 109, 2111.

Gutman, A. B., Swenson, P. C., and Parsons, W. B. (1934). Ibid., 103, 87.

Harris, H. A. (1933). "'Bone Growth in Health and Disease", pp. 85 and 181, London.

Hunter, D. (1930). Lancet, 1, 947.

-, and Turnbull, H. M. (1931-2). Brit. J. Surg., 19, 203.

Jaffe, H. L., Bodansky, A., and Chandler, J. P. (1932). J. exp. Med., 56, 823.

Lance, M., Girard, L., and Lance, P. (1938). Rev. D'Orthop., 25, 385.

Leitch, I. (1936-7). Nutrition Abstr. and Rev., 6, 553.

McGowan, J. P. (1933). Brit. med. J., 2, 599.

Maxwell, J. P. (1929-30). Proc. roy. Soc. Med., 23, 639.

Meulengracht, E. (1938). Lancet, 2, 774.

(1939). Acta med. Scand., 101, 138.

-, and Meyer, A. R. (1936). Ugeskr. Laeg., 98, 961. Quoted by Owen (1939).

Morris, N., and Peden, O. D. (1937). Quart. J. Med., N.S., 6, 211.

Orr, J. B. (1937). “Food, Health and Income". 2nd ed., London.

Owen, E. C. (1939). Biochem. J., 33, 22.

, Irving, J. T., and Lyall, A. (1939). Acta med. Scand., 103, 235.

Ravault, P. P., Graber-Duvernay, J., and Léger, G. (1939). 'J. méd. Lyon, $20,69$.

Robertson, J. D. (1941). Lancet, $2,97$.

Schmidt, C. L. A., and Greenberg, D. M. (1935). Physiol. Rev., 15, 297.

Schmorl, G. (1926). Verhandl. deutsch. orthop. Gesellsch., 21, 71. Quoted by Black et al. (1941).

- (1931). Beitr. path. Anat. allg. Path., 87, 585.

Sherman, H. C., Rose A. R., and Rose, M. S. (1920). J. Biol. Chem., 44, 21.

Shohl, A. T., and Pedley, F. G. (1922). Ibid., 50, 537.

Silberberg, M., and Silberberg, R. (1943). Arch. Pathol., 36, 512.

Youngburg, G. E., and Youngburg, M. V. (1930). J. Lab. clin. Med., 16, 158. 